\title{
On the Key Points of College English Teaching from the Perspective of Humanistic Education in the New Situation
}

\author{
Xuemei Zhu \\ Colloge of Foreign Languages and Literature, Wuhan Donghu University, Wuhan Hubei, 430070, \\ China
}

Key words: Humanities education, English teaching, New situation, University.

\begin{abstract}
College English teaching has humanistic characteristics, humanistic means to carry forward and highlight the value of people, so that people-oriented, respect for people, the transfer of positive energy. When reforming English teaching, humanistic education should be taken as the starting point, and the practical knowledge of humanism should be transmitted in teaching, focusing on cultivating humanistic accomplishment and turning knowledge into thinking quality and emotion. When the humanities education is the starting point of teaching reform, we should take into account the requirements of professional education, handle the relationship between applied subject and humanistic education, and use the methods of spiritual nourishment, practical experience, environmental protection, Teaching, to avoid one-way indoctrination of knowledge, to cultivate the humanistic spirit, shaping personality and guiding human values. This paper explores the main points of college English teaching in the new situation, which aims at effectively solving the teaching reform dilemma.
\end{abstract}

\section{Introduction}

College English courses cover a wide range of hours, high attention, teaching methods, teaching content, teaching methods, teaching objectives and teaching ideas can have an impact on student employment or further study, according to higher education requirements of a comprehensive reform of English teaching, Expand the curriculum and highlight the personality education, training listening and speaking ability, communication skills and other applications. When reforming English teaching, we should choose the starting point from the strategic point of view of social stability and national interests, pay attention to the situation, so that students can improve their humanistic accomplishment, academic literacy, professional knowledge and ability to cultivate more proficiency in English by learning English Of the people, the national military, diplomatic, political, cultural, social and economic development have a role in promoting [1]. To improve the humanistic accomplishment is an important development direction of teaching reform. Under the new situation, the humanistic education perspective should be taken as the point of teaching reform, and the key points of reform should be grasped.

\section{Humanities education and English teaching}

English language is a language subject, the language can not only convey information, but also the expression of cultural connotation, reflecting the history, with the role of media and cultural characteristics. Therefore, the English discipline carries a lot of thought and humanistic spirit, at the same time play a role in the transmission of humanistic spirit, humanities education, English teaching has some common ground. Reform of English teaching can be humanistic education as a starting point, and in the process of reform to promote English teaching, humanities education to achieve effective integration. And comprehensively enhance the ability of foreign language listening, speaking, reading and writing of college students on the basis of combining English culture and humanistic spirit. At the same time, we can cultivate expression ability, thinking ability, aesthetic ability, ability of discussion and communication ability, Collective concept, cooperative consciousness, national consciousness and self-awareness and other humanistic spirit ${ }^{[2]}$. In order to 
ensure that the entry point of English teaching reform is humanistic education, it is necessary to ensure that humanistic education has always run through all aspects of teaching reform. First, we should pay attention to the rise of English teaching to human level or consciousness level, and integrate human composition into teaching philosophy. In the teaching not only to guide students to learn English knowledge, but also to expand their horizons, cultivate divergent thinking, so that students can view the problem from the human perspective, to achieve cognitive leap, change behavior, thinking. Secondly, it should lead the direction of teaching reform from the perspective of humanities, and change the English teaching according to the new situation of informationization and globalization, and use the flexible knowledge transmission mode to meet the learning needs of college students effectively ${ }^{[3]}$. In addition, the English teaching process can be used as the process of Western cultural communication, so that college students can learn in the English classroom rich in Western culture, clear oriental culture and Western culture differences in the process of learning culture to enhance the quality of humanities. But also lies in the teaching of Western cultural emphasis on moral, sentiment and other humanistic spirit.

\section{The reform points under new situation}

\section{In the teaching design through the humanities education}

Teaching design determines the teaching content and teaching mode, the reform of English teaching should be in the teaching design through humanistic education, to ensure that the teaching design program in line with humanistic education theory. First of all, teaching design should focus on the introduction of humanistic spirit. In the introduction of teaching theme, should be combined with the corresponding background of human knowledge, organic combination of cultural background and language knowledge, so that students can learn English knowledge in the process of understanding human knowledge, thereby enhancing the humanities awareness ${ }^{[4]}$. For example, in the teaching of environmental protection content can be introduced with the theme of the text related to the era of vocabulary, such as green collar, low-carbon living, greenhouse effect and global warming, the use of distinctive English vocabulary to guide students to expand teaching theme, So that students in the teaching of deep thinking about environmental protection, social development, the relationship between. In addition, for the theme of integrity teaching, you can use the "Is the honesty going out of our style" into the teaching theme, so that students on the university campus exam cheating phenomenon to explore, teachers in the teaching that the integrity of the conduct, Of the base, should be honest and trustworthy, law-abiding, put an end to the test cheating. Second, you can design in the teaching of humanistic color of the classroom activities, so that students participate in classroom activities in the process of deep understanding of the implication in the English knowledge of humanistic spirit. You can let the students perform with the teaching theme related to the scene, people, or for the teaching theme of the organization speech contest, in the teaching activities to experience the feelings of the characters. For example, after teaching "Marriage Across Nation", you can first introduce the historical background, cause the students' interest, and then let the students to the text content and characters to carefully dig, to show the form of text content, or let the students according to their understanding of marriage Write the end of Mark and Gail. In addition, the teaching design should be combined with professional knowledge, professional differences, the integration of humanistic education content should be some differences to ensure that English teaching can provide good protection for professional learning ${ }^{[5]}$.

\section{Using Context Teaching to Strengthen Humanistic Education}

Contexts include cultural context, contextual context and linguistic context. Linguistic phenomena, linguistic phenomena, linguistic meaning and linguistic forms in different contexts can make people have different interpretations. In the reform of English teaching, Grammar, word and context are isolated, we should pay attention to explain the meaning of discourse in specific context, so that students can correctly understand the meaning of words, and clear the discourse embodies the 
humanities knowledge, so in the context of teaching effectively strengthen human education. In the use of contextual teaching to strengthen humanistic education, we can first use metaphor to carry out context teaching. Metaphor is a highly creative human language, can be mechanical and boring philosophy into an easy to accept the language, the use of metaphor to strengthen the context of teaching and humanities education, students can be in the English classroom in a relatively easy way to accept The will of the behavior of norms, the connotation of life and other human knowledge, while improving the spirit of building a model to improve the love of education, self-education, life education, education and communication education and other humanities education efficiency ${ }^{[6]}$. For example, "Steer ship with hope, I endure behind", ship meaning refers to the ship, steer the original meaning refers to the driving, maritime metaphor is life, in the navigation will encounter a variety of challenges and threats, so life is often But also inadvertently appear not smooth and bumpy, but to full of hope for life, to maintain fearless, optimistic attitude towards setbacks. For example, you can use "Apple of sb's eye" and "Sad is down, happy is up" and other metaphors in the teaching of students to instill humanism. Secondly, sentences or vocabulary can be placed in a specific context, in the teaching emphasizes the sentence and the vocabulary embodies the connotation and humanistic knowledge. In addition, it is necessary to carry out discourse teaching in the context of culture and context, compare culture in specific contexts, discuss topics and convey humanistic thoughts.

\section{Make full use of humanistic educational resources in teaching materials}

In the reform of English teaching, we should make full use of the humanities education resources in the teaching materials so as to optimize the teaching reform effect, and to improve the teaching effect of the teaching materials, At the same time in the reform to implement the spirit of humanism. In the use of teaching materials in the human resources, we should pay attention to identify the entry point, in teaching at the same time play the role of language media and human cultural channels ${ }^{[7]}$. For the Western original textbooks, care should be taken to avoid the students in the process of exposure to the original textbooks by the impact of bad ideas, and can be in the original textbooks to understand the Western scientific research and cultural heritage. When selecting materials with humanistic educational significance, the principle of transmitting positive energy should be used. For example, you can use the contents of the "Celebration of the holiday" as an educational resource in the teaching materials, explain the traditional Chinese festivals to the students in the teaching, and appropriately contrast the traditional Chinese festivals and enhance the students' sense of responsibility and self-esteem The You can also choose on the theme of Love, Success and Wealth teaching materials for humanistic education, so that students can appreciate the precious friendship, family, or the use of "the Man in Asbestos" and "Quick Fix Society" and other fast-paced life on the human Physical and psychological impact, so that students learn to adjust the pace of life, return to nature. In order to ensure that the content of teaching materials can play the role of humanities education, in the use of human resources in teaching materials to carry out English teaching, should pay attention to guide students in the preview phase of independent search and understanding of the corresponding background knowledge, in-depth understanding of the article in the textbook, Classroom should pay attention to in-depth analysis of the text, in the process of analysis of the excavation of humanistic spirit, and guide students to extend the content of teaching materials to read and think, by thinking about the humanities to cultivate a positive outlook on life and health emotions ${ }^{[8]}$.

\section{Using New Media to Integrate Humanistic Education in Teaching}

New media with convenient, cost-effective and other characteristics, college students to use the new media to the Internet, WeChat, microblogging, QQ, etc., in the teaching of the use of new media, help to build a teaching community, effective integration of teaching in human education [9]. First of all, the use of information resources can be more rich Internet implementation of English teaching reform, the use of the network will be English culture, human knowledge into the English classroom, to stimulate students' initiative in English teaching, while ensuring the full interaction of English teaching process. For example, in explaining the relevant degree knowledge, you can first inform students to use the Internet to find the characteristics of the higher education system of Western 
countries, so that students can initially understand the higher education in China and Western countries, the existence of higher education, teachers can be carried out in the classroom Appropriate supplement, such as vocation, academic, certificate, diploma, advanced degree and other knowledge, so as to help students accumulate more human knowledge. Second, you can use Weibo in teaching, QQ and WeChat integration of humanities education. For example, you can spread health knowledge in Weibo, like"A good conscience is a continual feast"、"There is a calmness to a life lived in gratitude, a quiet joy"、"Learn to work and rest"、"Little eat meat, and eats the vegetables more"、 "It is not work that kills, but worry"etc. In addition, in the use of new media to reform English teaching, to ensure effective interaction between teachers and students, commonly used interactive methods, including task-driven and output-driven. For example, when the festival is near, you can use the task-driven method to achieve interaction, asking students to find Easter, Valentine's Day, Christmas, Thanksgiving Day and Halloween and other holiday information [10]. In addition, students can use the network to collect information, organize the information, and in the classroom to express their views, or the data compiled into PPT, such as the Egyptian pyramids, Mayan civilization, the Bermuda Triangle, Mysterious phenomenon and Marriage culture, Show in the classroom. In this way, you can let students in the independent access to information, to explore the process of learning to learn more human knowledge, while expanding the ability of English knowledge application.

Conclusion:

All in all, in the new situation, the lack of humanistic quality can seriously affect the quality of higher education. In the reform of English teaching, we should attach importance to the implementation of humanistic education in order to cultivate humanistic accomplishment, enhance students' team spirit, interpersonal communication ability, language application ability, pioneering and innovative ability The From the perspective of humanistic education, we should create a diversified and personalized curriculum module, fully integrate and innovate all kinds of teaching elements, and reposition the teaching objectives, curriculum value and teaching framework according to the tide of internationalization, informationization and globalization , To strengthen the sense of change. In addition, when reforming English teaching, we should take into account the characteristics of English learning and learning rules of college students, and actively sum up the experience of teaching reform, absorb good educational traditions, teaching theory, innovative teaching system and teaching reform mechanism, unified planning English teaching, , The guiding principles of teaching.

\section{Acknowledgement}

Topic: Research on the Reform of College English Teaching in the Perspective of Humanistic Education in the Province of Hubei Province in 2015 (No. 2015432).

\section{References}

[1] Yu Shanshan. Experiments and Explorations of College English Teaching Reform - Based on the Theory of "Output Driven - Input Promote Hypothesis. Journal of Changsha University of Science and Technology (Social Science Edition), 2017,32 (1): 134-138.

[2] Zhu Hongmei, Zi Ying. Cultural Turnover of College English Teaching Reform under Modern Technology Support and Teaching Networkization - Taking Beijing Forestry University as an Example, Journal of Forestry Education, 2017,35 (1): 76- 78.

[3] Zuo Yingjuan, Feng Lei.Study on the Standard Scale of College English Writing - Based on the Comparison of Writingroadmap and Correction Network, Modern Educational Technology, 2015,25 (8): 60-66. 
[4] Lv Tingting, Wang Na. Study on the Teaching Mode of Inverted Classroom Based on SPOC + Digital Teaching Resource Platform - Taking College English as an Example, China Electrotechnical Education, 2016 (5): 85-90.

[5] Li Ye, Zhao Dongmei. Study on the Discourse Investigation of "College English" Micro-course Teachers and Its Teaching Effect - Taking the Winners of the First Chinese Foreign Language Course as a Sample, Foreign Language Teaching, 2015 (5): 15-20.

[6] Yi Jingbo. Educational publishing media integration of the development and trends - to university English textbooks published as an example, Published wide angle, 2017 (23): 32-34.

[7] Yu Yang. Analysis of CDIO Mode of Science and Technology English Translation Teaching Reform and Practice - Chengdu University of Information Engineering as an example, Overseas English, 2016 (21): 49-57.

[8] Chang Lang. Non-English Majors' Academic English Communicative Competence: A Case Study of Yan'an University-Take Yanan University as the Example, Journal of Xichang University (Social Science Edition), 2016,28 (1): 139-141

[9] Guli Mila, Abu Laity, Sheng Hui. A Study on the Characteristics of the Application of Word Blocks in the Writing of Non - English Majors - Taking Xinjiang Normal University as an Example, Journal of Changchun Institute of Education, 2015,31 (24): 83-84.

[10]Gu Ying. Multi-mode theory based on the design of college English writing teaching - to college English quaternary test "picture class composition" as an example, English square (academic research), 2015 (5): 37- 38. 